\title{
Growth of the Masseter Muscle in Rhesus Monkeys (Macaca mulatta)
}

\author{
DAVID S. CARLSON \\ Department of Anatomy and Cell Biology and Center for Human Growth \\ and Development, The University of Michigan, Ann Arbor, Michigan 48109
}

KEY WORDS Masseter muscle, Craniofacial growth, Macaca mulatta, Cephalometrics

\begin{abstract}
The growth of the masseter muscle in eight infant, juvenile, and adolescent female rhesus monkeys ( $M$. mulatta) was examined over a 2.5 year period using serial radiographic cephalometric techniques with the aid of radiopaque muscle markers. The radiopaque markers, which are composed of small pieces of root canal broach inserted into the muscle belly, make it possible to determine longitudinal masseter muscle growth as well as migration of the masseter muscle relative to the mandible. It was found that the masseter muscle increased in length by $64 \%$ during the total growth period, most of which occurred between 6 and 18 months of age. Relative to the cranium, the masseter muscle grew markedly inferiorly and only slightly posteriorly. Relative to the mandible, the masseter migrated in a posterior and slightly superior direction, keeping pace with the ramus and condyle as they grew posteriorly and posterosuperiorly throughout the study period. It was concluded that: 1) radiopaque muscle markers are a valuable tool for analysis of muscle growth and alteration of muscle location; 2) the masseter muscle in the rhesus monkey undergoes elongation, probably due to addition of sarcomeres at the fiber-tendon junctions; and 3) posterior migration of the masseter muscle relative to the corpus of the mandible, probably due to the nature of its periosteal attachment, results in a stability of the anteroposterior position of the masseter muscle despite the anterior displacement of the mandible.
\end{abstract}

The published research concerning the growth and form of the skeletal tissues comprising the craniofacial complex is extensive. The reason for this is two-fold. First, the growth and form of the craniofacial skeleton and dentition is of primary concern to craniofacial biologists and clinicians alike since it determines facial appearance and occlusal relationships. Second, preoccupation with the skeletal tissues of the craniofacial complex is due, at least in part, to the methods available for their longitudinal analysis. Radiographic cephalometric methods make it possible not only to image and record the form of the craniofacial skeleton and dentition at a single point in time, but also to infer growth processes by taking serial radiographic cephalograms over multiple time periods in the same individual. The addition of radiopaque bone implants to the armamentarium of the cephalometritian permitted a refinement of inferences concerning longitudinal skeletal growth by making it possible to superimpose serial cephalogarams more accurately and to separate the processes of transformational and translational skeletal growth (Björk, 1955, 1968; Björk and Skieller, 1972).

The muscles of the craniofacial complex have also always been of central concern to craniofacial biologists and clinicians, primarily because of the influence of muscle function on the growth and form of the craniofacial skeleton. With the exception of a study of the growth of the anterior belly of the diagastric muscle in rabbits by Muhl and Grimm (1974a) and a preliminary study of the growth of the masseter muscle in the miniature pig by Grimm and Katele (1979), there have been no longitudinal studies of the growth of the muscles of mastication that are comparable to the numerous serial radiographic analyses of craniofacial skeletal growth. That is, because of difficulties in precise determination of the location of a muscle or a part of the muscle using serial radiographic methods, there is very little that is

Received July 12, 1982; accepted October 20, 1982. 
known about the longitudinal growth of the muscles of mastication.

The purpose of this paper is to discuss a method for serial radiographic analysis of muscles and to describe the growth of the masseter muscle in young rhesus monkeys over a 2.5 year span. More specifically, changes in the length and position of the masseter muscle over a period of 120 weeks will be analyzed using the technique of radiographic cephalometry in infant, juvenile and adolescent female rhesus monkeys.

\section{MATERIALS AND METHODS Experimental animals}

Eight female rhesus monkeys (Macaca mulatta) were used in this study (Table 1). Three of the monkeys were born in our colony and were studied for a period of between 18 and 40 months beginning at 6 months of age. Analysis of the five additional monkeys began when they were estimated to be 18-24 months of age based upon the presence of first permanent molars in occlusion. These animals were studied for a period of from 6 to 18 months. Following the protocol of McNamara and Graber (1975) in a study of mandibular growth in the rhesus monkey, the entire sample was assigned to three groups on the basis of their dental eruption (Hurme and Van Wagenen, 1961). Infants (048 weeks of study) were characterized by a complete deciduous dentition; the juvenile period (48-96) weeks) began once the first permanent molars were in occlusion; the adolescent period (96-120 weeks), was characterized by a complete permanent dentition with the exception of unerupted third molars and partially erupted canines.

\section{Implant techniques}

Radiopaque tantalum implants were placed in the frontal bone, maxillary complex, mandible and cranial base according to a protocol adapted for use in monkeys (Elgoyhen et al., 1971; McNamara et al., 1976; Carlson et al., 1982).

Radiopaque markers were also implanted into the masseter muscles of each monkey according to a procedure adapted from the work of Muhl and coworkers (Muhl and Grimm, 1974a, b) for the study of adaptations in muscle and tendon length (McNamara et al., 1978; Carlson et al., 1982; Carlson and Schmeiderman, in press). Using aseptic procedures, gold barbed root canal broaches 2.5$3.0 \mathrm{~mm}$ in length and $0.7 \mathrm{~mm}$ in diameter were placed into the lument of an 18-gauge
TABLE 1. Distribution of monkeys by periods studied

\begin{tabular}{|c|c|c|c|c|}
\hline \multirow[b]{2}{*}{$\begin{array}{l}\text { Animal } \\
\text { Number }\end{array}$} & \multicolumn{4}{|c|}{ Study period (weeks) } \\
\hline & $\begin{array}{l}\text { Infant } \\
(0-48)\end{array}$ & $\begin{array}{c}\text { Juvenile } \\
\text { (48-96) }\end{array}$ & $\begin{array}{c}\text { Adolescent } \\
\text { (96-120) }\end{array}$ & $\begin{array}{c}\text { Total } \\
\text { periods }\end{array}$ \\
\hline $1^{1}$ & $\mathbf{x}$ & $\mathbf{x}$ & & 2 \\
\hline $2^{1}$ & $\mathbf{x}$ & $\mathbf{x}$ & $\mathbf{x}$ & 3 \\
\hline $\mathbf{3}^{1}$ & $x$ & $\mathbf{x}$ & & 2 \\
\hline 4 & & $\mathbf{x}$ & $x$ & 2 \\
\hline$\overline{5}$ & & $\mathbf{x}$ & $\bar{x}$ & 2 \\
\hline 6 & & $\mathbf{x}$ & $\bar{x}$ & $\overline{2}$ \\
\hline 7 & & $\mathbf{x}$ & $\bar{x}$ & $\overline{2}$ \\
\hline 8 & & $\mathbf{x}$ & $\mathbf{x}$ & 2 \\
\hline$\ldots$ & $\ldots$ & - & - & \\
\hline $\mathbf{n}$ & 3 & 8 & 6 & \\
\hline
\end{tabular}

'Birth date known.

hypodermic needle. The needles were then inserted through the skin into the distal aspect of the belly of the right masseter muscle along its longitudinal axis and were expelled using a wire inserted through the hub of the hypodermic needle. This procedure was repeated so that muscle markers were placed in the anterior, middle, and posterior regions of the distal aspect of the masseter muscle. The same procedure was then repeated for the left side using broaches cut 3.5-4.0 mm in length and $0.05 \mathrm{~mm}$ in diameter. This difference in broach size made it possible to distinguish the two masseter muscles from each other radiographically. Only the middle muscle marker on the right side was used for quantitative analysis in this study.

Serial radiographic cephalograms with the head in a standardized lateral position (McNamara, 1972) were taken of each monkey immediately after the markers were implanted and every week thereafter until the markers were stable (Fig. 1). Muscle marker stability, which was defined as the time at which superimposed weekly serial cephalograms failed to reveal any movement of the muscle markers among themselves, was found to occur approximately 6 and 8 weeks after implantation. Previous studies have shown that masseter muscle markers in nongrowing control adult monkeys vary in position by less than $1.0 \mathrm{~mm}$ during a 1 year period, and that this positional variability is nondirectional (McNamara et al., 1978). Thus, that amount of variability in the position of the muscle marker is more likely due to small variations in head position at the time of x-raying than in muscle marker movement. Analysis of masseter muscle growth was not begun until the muscle markers were judged to be stable. 


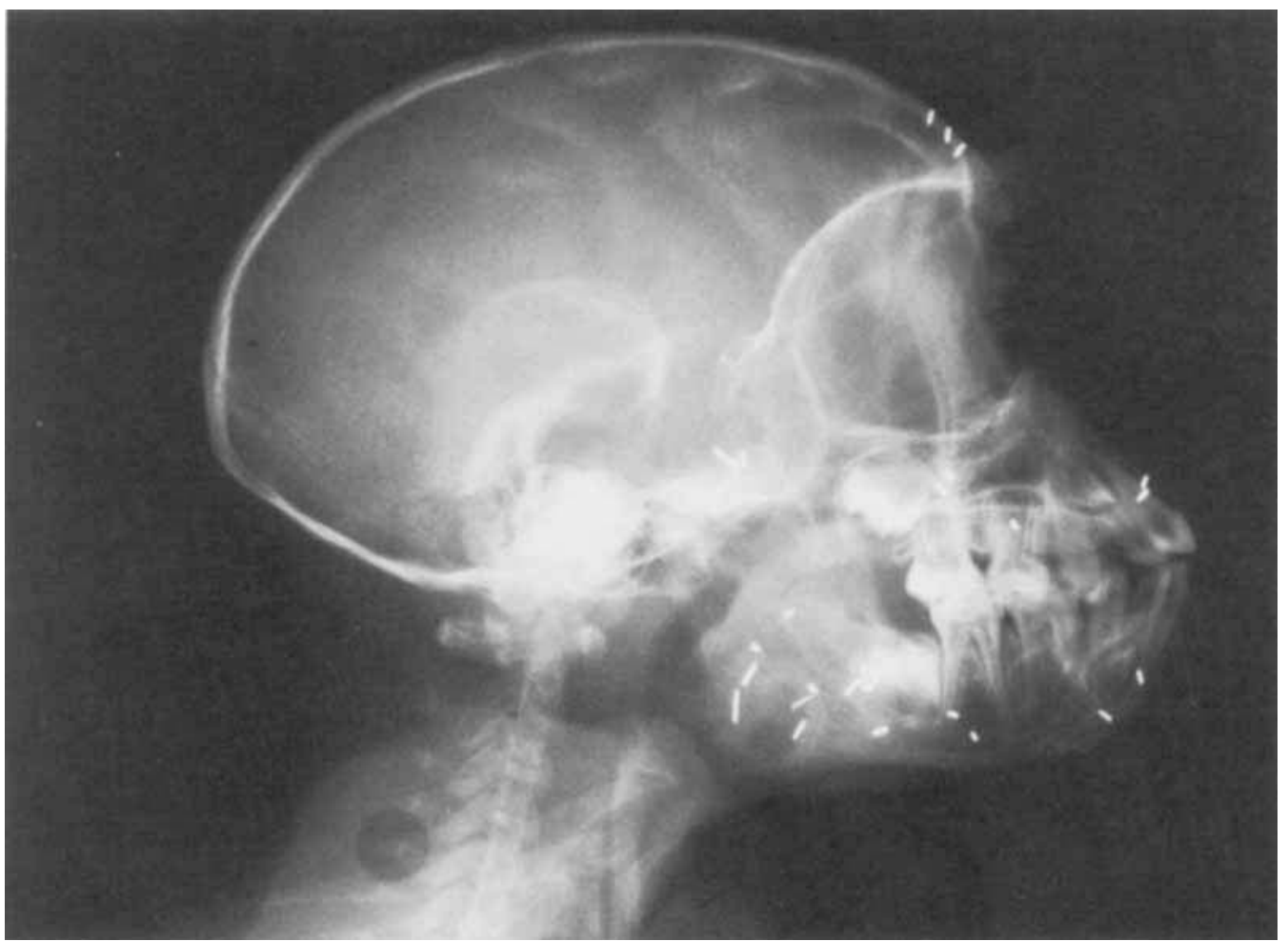

Fig. 1. Lateral radiographic cephalogram of an infant rhesus monkey with a full deciduous dentition. Note the position of the radiopaque bone markers throughout the craniofacial skeletal complex and of the radiopaque muscle markers in the distal one-half of the masseter muscle.

\section{Cephalometric analysis}

Each monkey was radiographed once the muscle markers were stable and every 24 weeks thereafter. Radiographic cephalograms were traced and digitized to record the $x, y$ coordinates of the radiopaque bone and muscle markers, as well as of 58 anatomic landmarks and reference points. These data were entered into the Michigan Terminal System for graphic and quantitative analysis.

Two reference axes were constructed for quantitative analysis of the growth of the masseter muscle and maxillomandibular skeleton (Fig. 2). The cranial reference axis was constructed by passing a perpendicular to a line parallel to the original occlusal plane that passed through one of the cranial base bone implants (CRL). Serial radiographs were then superimposed using the cranial base implants, and the original CRL was used as a reference for measurements of mandibular and masseter growth relative to the cranium. The mandibular reference axis was constructed by passing a perpendicular through a line parallel to the original occlusal plane through a bone implant in the mandibular corpus (MRL). Serial radiographs were superimposed using the mandibular implants and the original MRL was used as a reference for measurements of masseter muscle and condylar growth relative to the mandible itself.

Six variables were used to describe the growth of the masseter muscle relative to the maxillomandibular skeleton (Fig. 3). Condylar growth was determined by measuring the horizontal and vertical position of condylion, i.e., the most posterior and superior point along the condyle, between serial cephalograms relative to the mandibular reference axis. The growth of the masseter muscle was determined by measuring the change in the horizontal and vertical position of the mas- 


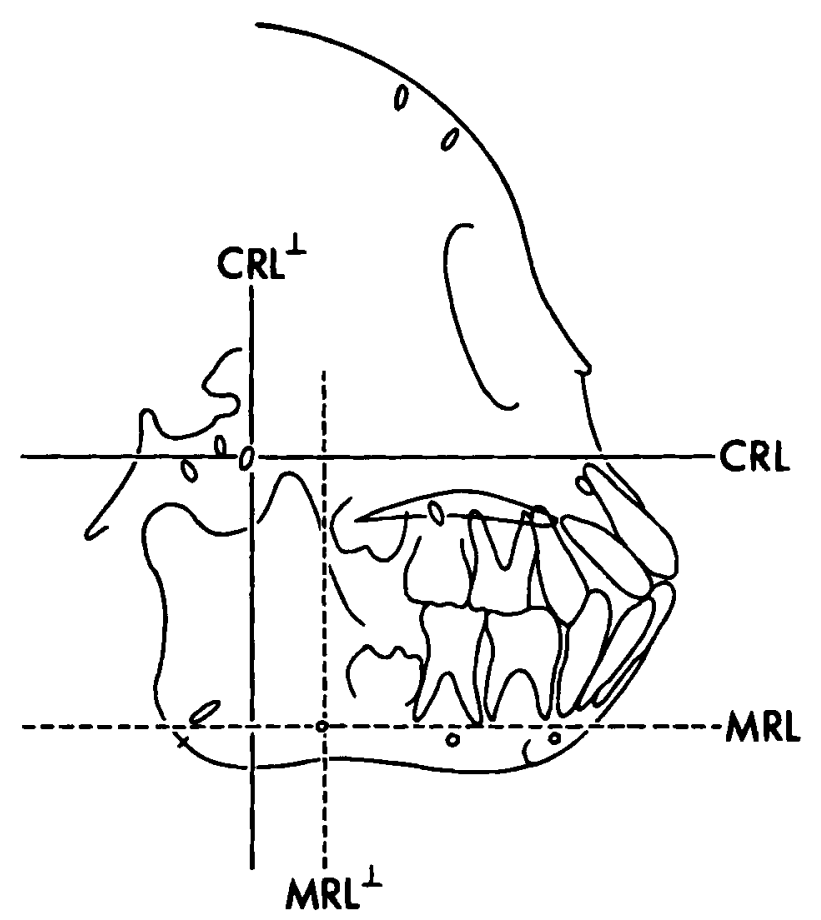

Fig. 2. Diagram indicating the construction of the cranial reference axis and mandibular reference axis systems.

seter muscle marker relative both to the cranial reference axis (MM/CRL) and to the mandibular reference axis (MM/MRL) between serial cephalograms. The position of gonion was recorded in the same manner, i.e., relative to the cranial reference axis (GO/ CRL) and to the mandibular reference axis (GO/MRL), in order to determine whether the masseter muscle changed position relative to the gonial region. Finally, masseter length was measured from the zygomaxillary bone implant, the most anterior attachment of the masseter muscle, to the masseter muscle marker. Using this approach, it was possible to determine serial growth changes in the length and position of the masseter muscle relative to the growth related changes in the size and shape of the mandible.

\section{RESULTS \\ Mandibular growth}

The growth of the maxillomandibular skeletal complex proceeded normally in all monkeys during the 120 week study period.
Relative to the cranial base, the maxillary skeleton grew anteriorly and slightly inferiorly. The mandible was displaced anteriorly and inferiorly with the maxilla, while the temporomandibular joint became posteriorly relocated.

Superimposition of serial cephalograms on the mandibular bone implants (Table 2) revealed that the entire ramus was depository along its posterior border. The condylar region grew in a posterosuperior direction an average of $21.1 \mathrm{~mm}$ during the 120 week period. The rate and amount of condylar growth varied somewhat, with $51 \%$ of the total average condylar growth occurring during the first 48 week period (infant period), an average of $35 \%$ during the juvenile period and 23\% during the adolescent period. Normal remodeling of the gonial region took place as bone was deposited along the posterior border of the ramus. The result was a marked inferior and slight posterior movement of gonion relative to the cranial reference axis. Relative to the mandibular 

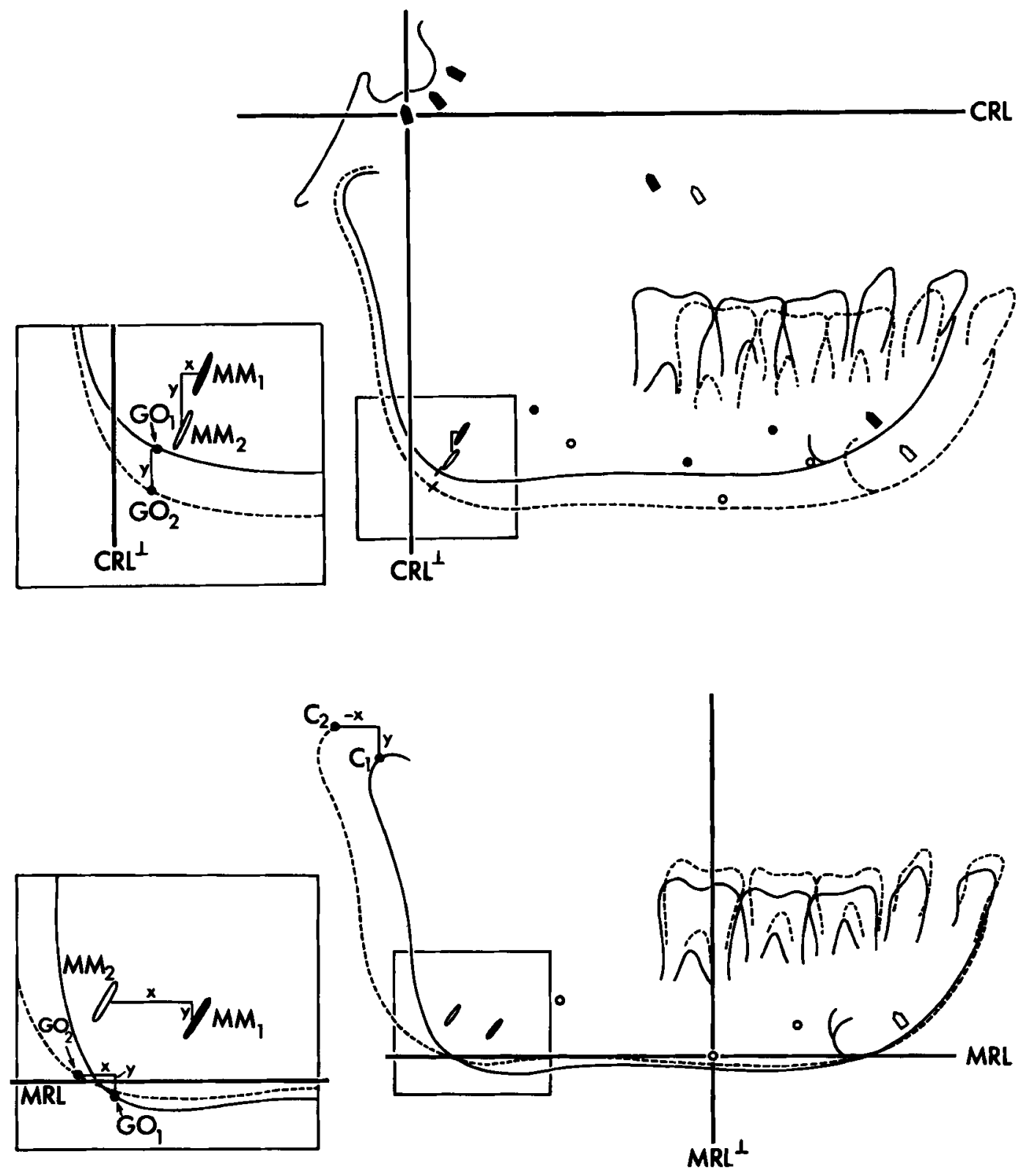

Fig. 3. Diagram indicating the method by which the phalograms relative to the cranial reference axis (top) movement of the masseter muscle marker, condylion and to the mandibular reference axis (bottom). 
TABLE 2. Growth related changes in the mandibular condyle, masseter muscle, and gonial region during 24-week intervals among infant, juvenile, and adolescent female rhesus monkeys

\begin{tabular}{|c|c|c|c|c|c|c|c|c|c|c|}
\hline \multirow[b]{3}{*}{ Measurement } & \multicolumn{4}{|c|}{ Infant $(n=3)$} & \multicolumn{4}{|c|}{ Juvenile (n=8) } & \multirow{2}{*}{\multicolumn{2}{|c|}{$\frac{\text { Adolescent }(n=6)}{96-120}$}} \\
\hline & \multicolumn{2}{|c|}{$0-24$} & \multicolumn{2}{|c|}{$24-48$} & \multicolumn{2}{|c|}{$48-72$} & \multicolumn{2}{|c|}{$72-96$} & & \\
\hline & $\overline{\bar{x}}$ & sd & $\overline{\mathbf{x}}$ & sd & $\overline{\mathbf{x}}$ & sd & $\overline{\mathbf{x}}$ & sd & $\overline{\mathbf{x}}$ & sd \\
\hline Condylar growth & & & & & & & & & & \\
\hline $\mathbf{x}$ & $\begin{array}{r}-4.12 \\
4.60\end{array}$ & $\begin{array}{l}0.29 \\
2.10\end{array}$ & $\begin{array}{r}-2.87 \\
3.67\end{array}$ & $\begin{array}{l}0.42 \\
0.58\end{array}$ & $\begin{array}{r}-3.31 \\
2.90\end{array}$ & $\begin{array}{l}0.99 \\
2.37\end{array}$ & $\begin{array}{r}-1.73 \\
2.47\end{array}$ & $\begin{array}{l}0.44 \\
0.81\end{array}$ & $\begin{array}{r}-2.15 \\
3.23\end{array}$ & $\begin{array}{l}1.02 \\
1.97\end{array}$ \\
\hline$\underset{\mathbf{x}}{\mathrm{MM} / \mathrm{CRL}}$ & -1.33 & & & & & & & & & \\
\hline$\stackrel{\mathbf{x}}{\mathbf{y}}$ & $\begin{array}{l}-1.35 \\
-4.10\end{array}$ & $\begin{array}{l}0.28 \\
1.67\end{array}$ & $\begin{array}{l}-0.04 \\
-1.66\end{array}$ & 0.2 & -2.76 & 0.85 & -1.40 & 0.57 & $\begin{array}{l}-1.42 \\
-0.17\end{array}$ & $\begin{array}{l}.03 \\
0.36\end{array}$ \\
\hline $\begin{array}{l}\mathbf{x} \\
\mathbf{y}\end{array}$ & $\begin{array}{r}-5.53 \\
2.51\end{array}$ & $\begin{array}{l}1.53 \\
0.86\end{array}$ & $\begin{array}{r}-1.73 \\
0.25\end{array}$ & $\begin{array}{l}1.20 \\
0.36\end{array}$ & $\begin{array}{r}-4.68 \\
1.18\end{array}$ & $\begin{array}{l}2.11 \\
1.95\end{array}$ & $\begin{array}{r}-2.08 \\
0.61\end{array}$ & $\begin{array}{l}1.15 \\
0.67\end{array}$ & $\begin{array}{r}-3.53 \\
2.65\end{array}$ & $\begin{array}{l}2.05 \\
1.41\end{array}$ \\
\hline $\begin{array}{c}\text { GO/CRL } \\
\mathbf{x} \\
\mathbf{y} \\
\text { GOMRL }\end{array}$ & $\begin{array}{l}-1.71 \\
-3.62\end{array}$ & $\begin{array}{l}1.21 \\
1.65\end{array}$ & $\begin{array}{l}-0.46 \\
-2.10\end{array}$ & $\begin{array}{l}0.40 \\
0.17\end{array}$ & $\begin{array}{l}-0.68 \\
-3.11\end{array}$ & $\begin{array}{l}0.65 \\
0.96\end{array}$ & $\begin{array}{l}-0.52 \\
-1.51\end{array}$ & $\begin{array}{l}0.30 \\
0.49\end{array}$ & $\begin{array}{l}-0.32 \\
-1.50\end{array}$ & $\begin{array}{l}0.26 \\
0.71\end{array}$ \\
\hline $\begin{array}{l}\mathbf{x} \\
\mathbf{y} \\
\text { Masseter length }\end{array}$ & $\begin{array}{r}-3.91 \\
0.66 \\
4.83\end{array}$ & $\begin{array}{l}1.01 \\
0.65 \\
2.10\end{array}$ & $\begin{array}{r}-2.43 \\
0.23 \\
6.07\end{array}$ & $\begin{array}{l}1.16 \\
0.76 \\
0.23\end{array}$ & $\begin{array}{r}-4.15 \\
1.30 \\
3.14\end{array}$ & $\begin{array}{l}1.22 \\
0.54 \\
0.69\end{array}$ & $\begin{array}{r}-2.25 \\
0.83 \\
2.60\end{array}$ & $\begin{array}{l}0.49 \\
0.55 \\
1.29\end{array}$ & $\begin{array}{r}-3.82 \\
2.12 \\
2.25\end{array}$ & $\begin{array}{l}0.99 \\
0.75 \\
0.96\end{array}$ \\
\hline
\end{tabular}

reference axis, however, gonion moved markedly posteriorly and, to a lesser extent, superiorly.

\section{Masseter muscle growth}

Masseter length: The masseter muscle increased in length by an average of $64 \%$ (18.8 $\mathrm{mm}$ ) during the entire study period. The greatest amount of total increase in masseter muscle length (49\%) took place during the infant period, with progressively less increase in masseter length occurring during the juvenile (35\%) and adolescent (16\%) periods.

Masseter position: The position of the masseter muscle during growth paralleled closely the position of the gonial angle of the mandible. Relative to the cranial reference axis, the masseter muscle moved inferiorly and slightly posteriorly throughout the growth period. Superimposing on the mandibular bone implants and mandibular reference axis, it was possible to discern the extent to which the masseter muscle migrated during growth. Relative to the mandible itself, the masseter muscle migrated markedly posteriorly and slightly superiorly along the ramus during the 120 week study period.

\section{DISCUSSION}

Postnatal growth of striated muscle fibers is primarily the result of two basic processes-fiber hypertrophy through addition of myofibrils within each fiber and elongation as a result of addition of sarcomeres within fibers. The exact mechanism and stimulus that bring about fiber hypertrophy are not known; however, it is well known that function, both in terms of tension development and recruitment pattern, affects synthesis of myofibrils (Goldspink, 1980). During normal growth, muscles may change with respect to their function and with respect to the levels of tension necessary to support and move an increasing body mass, and thus, undergo hypertrophy normally as animals grow in mass and mature (Stewart, 1972; Goldspink and Williams, 1980).

Several earlier studies suggested that muscle fibers grow in length by addition of sarcomeres at their fiber-tendon junction (Schmidt, 1927; Speidel, 1934). Studies of limb muscles by Crawford (1954) and Mackay and Harrop (1969) and of the anterior digastric muscle by Muhl and Grimm (1974a) using radiographic methods similar to those described in this study also support the hy. pothesis that interstitial muscle growth occurs primarily by addition of sarcomeres at the ends of the fibers comprising the muscle. This hypothesis was confirmed by Griffin and coworkers (1971) and Williams and Goldspink (1971), who used autoradiographic methods to demonstrate greater protein synthesis at the terminal ends of the muscle fibers.

Although it is now clear that muscle fibers grow by addition of sarcomeres at the fibertendon junctions, and that whole pennate muscles grow interstitially primarily by an 
increase in the length of the fibers comprising the muscle, once again the exact stimulus for longitudinal growth is unclear. It is known, however, that stretching and shortening a muscle greatly affect sarcomere number per fiber and, thus, overall fiber length. Experimental studies of the effect of changing the length of limb muscles by means of immobilization in different positions in adult animals have shown that increased muscle length results in an increase in fiber length due to increased sarcomere number, while decreased muscle length leads to a reduction in fiber length due to a decrease in sarcomere number (Tabary et al., 1972; Williams and Goldspink, 1971; Tardieu et al., 1973). Since this adaptation to change in muscle length occurs both in normally innervated muscle and in dennervated muscle, it is most likely the result of a myogenically mediated response, probably related to the overlap of actin and myosin filaments (Goldspink, 1980). During normal growth, passive stretch of muscles brought about by skeletal growth is the primary stimulus for longitudinal growth of the component fibers (Stewart, 1972; Goldspink, 1980).

Migration of muscle attachments also occurs during normal growth as the muscles maintain the same relative postions to the skeleton as the bone grows. This is most apparent in the growth of long bones and of their musculotendinous attachments (Lacroix, 1951; Grant and Hawes, 1977; Grant et al., 1978, 1980, 1981; Dörfl, 1980a,b). Muscles with fleshy, periosteal insertions, however, are also known to migrate during growth (Symons, 1954; Scott, 1954; Moss and MossSalentijn, 1978). The local mechanisms responsible for muscle migration may differ depending on both the site and type of muscle attachment, but it is clear that migration of muscles with tendinous and periosteal insertions occurs primarily as a result of the interstitial growth of the periosteum throughout its length (Grant et al., 1978, 1981; Moss and Moss-Salentijn, 1978; Dörfl, 1980a,b).

It is intuitively obvious that the masseter muscle increases in length during growth as the entire craniofacial complex increases in size. The data presented in this study, however, are the first to indicate empirically that the masseter muscle both elongates as a result of interstitial growth of the component fibers and migrates posteriorly during growth. It is not possible in this longitudinal analysis to prove that longitudinal growth of the masseter muscle occurs as a result of equal elongation of all fibers comprising the masseter muscle. However, concordance between inferior displacement of the mandible and longitudinal, inferior masseter growth as well as between the position of the masseter muscle and the gonial angle suggests that interstitial growth takes place throughout the muscle. Disproportionate growth of component fibers within the masseter would result in a lack of balance between these variables.

The extent of the migration of the masseter muscle during growth was a most interesting finding. Normal mandibular growth in primates is characterized by deposition of bone along the posterior border of the ramus, bone resorption along the anterior border of the ramus, and posterosuperior cartilaginous growth at the condyle (McNamara and Graber, 1975; Carlson et al., 1980). This results in a relatively consistent posterior and inferior relocation of the entire ramus during the growth period. The length and position of the masseter muscle in this analysis remained remarkably consistent with this pattern of mandibular growth, resulting in a marked inferior repositioning of the masseter muscle relative to the cranium and a simultaneous substantial posterior migration of the masseter muscle along the ramus. The net effect of this growth process was that the masseter muscle maintained the same relative anteroposterior position with the growing mandible while, simultaneously, the muscle was lengthened and the mandible was translated anteriorly (Fig. 4).

The specific mechanisms by which elongation of the masseter muscle came about are undoubtedly the same as those that operate within other skeletal muscles. Muscles attaching to long bones are placed under tension and become stretched as epiphyseal growth takes place, most likely stimulating synthesis of proteins within the muscle fibers and addition of sarcomeres resulting in longitudinal fiber growth (Stewart, 1972; Goldspink, 1980). In the same manner, the growing midface brings about an anterior and inferior translation of the mandible, stimulating not only condylar growth and skeletal remodeling along the ramus, but also addition of sarcomeres at the ends of the component fibers in order to alleviate this stretch.

The results concerning migration of the masseter muscle during growth can also be explained by essentially the same mecha- 


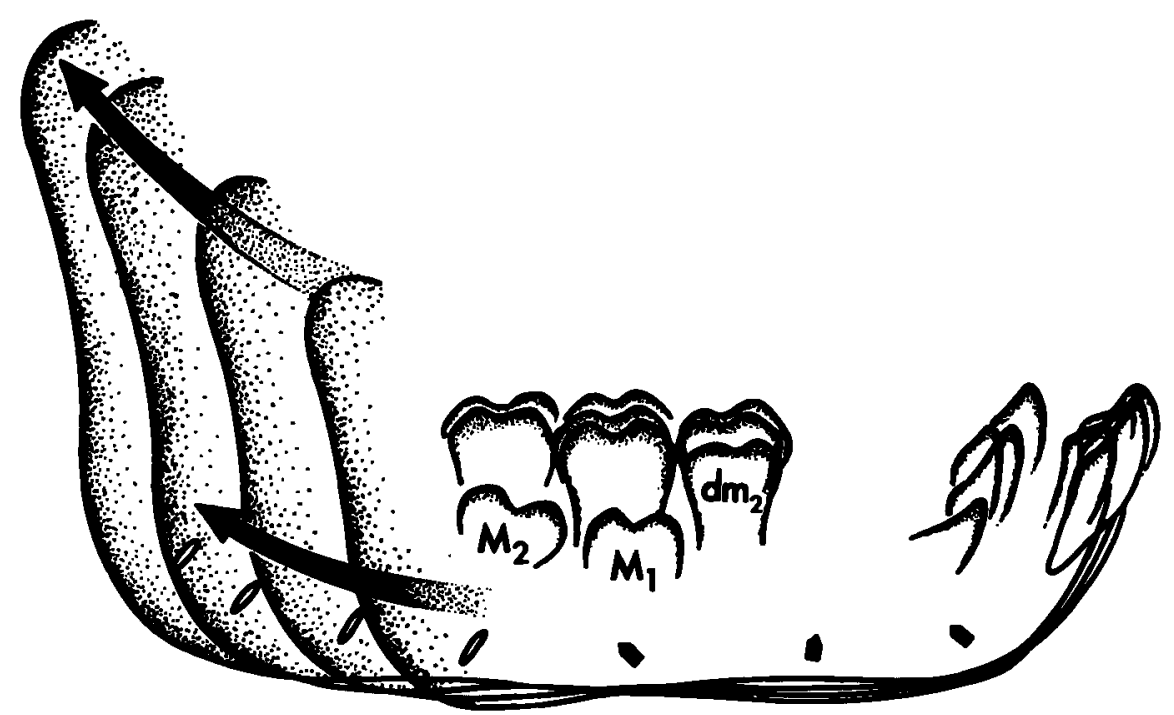

Fig. 4. Schematic diagram summarizing the change in the position of the masseter muscle markers relative to the growth of the mandible.

nisms as migration of muscle attachments along long bones. The masseter muscle in growing monkeys inserts via a fleshy attachment into the fibrous periosteum and not directly into bone (Symons, 1954). Deposition of bone along the posterior border and resorption of bone along the anterior border of the ramus of the mandible as it is translated anteriorly and inferiorly results in a net posterior translation of the periosteum with the ramus. Thus, the masseter muscle is translated posteriorly with its periosteal attachment. The overall result of this process is that the masseter muscle remains essentially stationary anteroposteriorly relative to the cranium and the periosteal envelope, while the mandible within the periosteal envelope is translated anteriorly and is remodeled to maintain its shape and to provide a structural base for that part of the periosteum into which the masseter muscle inserts. A similar process was noted by Grimm and Katele (1979) in their preliminary study of the growth of the masseter muscle in miniature pigs. They implanted a silver grain gelatin cylinder into the masseter muscle of growing pigs and found that the silver grains maintained their relative position within the muscle during growth while the mandible grew in an anterior direction. Since the underlying periosteum also exhibited a "trail" of silver grain particles, it was concluded that some posterior slippage of the muscle occurred at the interface between the fibrous layer of the periosteum and the fiber tendons. Thus, it is possible that some migration of the masseter muscle along the periosteum also occurs as the mandible grows anteriorly and inferiorly in primates.

\section{CONCLUSIONS}

Radiopaque implants composed of precious metal have a number of advantages for analysis of the growth, migration, and position of muscles and tendons. The technique for inserting the implants is relatively innocuous; after a period of only a few weeks, the implants are stable within the muscle and thus provide a means for precisely identifying the location of a muscle or tendon in a radiograph; and because implants of precious metal are not rejected, they can remain in place throughout the lifetime of the animal and thus provide a means of evaluating serial changes using radiographic techniques.

The serial radiographic cephalometric data revealed that the masseter muscle grows via two basic processes. First, the masseter muscle increased in length by an average of $64 \%$ from infancy through adolescence in female rhesus monkeys, a period of approximately 2.5 years. This longitudinal, interstitial growth of the masseter muscle was probably 
a result of addition of sarcomeres at the fibertendon junctions, and can be considered a compensatory, adaptive response of the fibers comprising the masseter muscle to passive stretch brought about by the inferior and anterior growth of the maxillomandibular skeletal complex. Second, the masseter muscle migrated posteriorly along the ramus of the mandible throughout the infancy-adolescence study period. The amount and direction of migration of the masseter muscle was completely concordant with the growth and remodeling of the ramus. As the mandible was displaced anteriorly and inferiorly during growth, the condyle and ramus grew posteriorly as a result of bone deposition along the posterior border and resorption along the anterior border of the ramus. The periosteal envelope, into which the masseter muscle inserts, remained in approximately the same anteroposterior position relative to the cranium. Thus, the masseter muscle became displaced posteriorly relative to the mandible itself, thereby maintaining the same anteroposterior position relative to the cranium.

\section{ACKNOWLEDGMENTS}

This research was funded by grants DE05232, DE03610, and DE00109 from the National Institute of Dental Research, National Institutes of Health.

\section{LITERATURE CITED}

Björk, A (1955) Facial growth in man, studied with the aid of metallic implants. Acta Odont. Scand. 13:1-34.

Björk, A (1968) The use of metallic implants in the study of facial growth in children: Method and application. Am. J. Phys. Anthrop. 29:243-254.

Björk, A, and Skieller, V (1972) Facial development and tooth eruption, an implant study at the age of puberty. Am. J. Orthod. 62:339-383.

Carlson, DS, McNamara, JA, Jr, Graber, LW, and Hoffman, DL (1980) Experimental studies of growth and adaptation of the temporomandibular joint. In WB Irby (ed): Current Concepts in Oral Surgery, Vol. III. St. Louis: C.V. Mosby Co., pp. 28-77.

Carlson, DS, Ellis, E, III, Schneiderman, ED, and Ungerleider, JC (1982) Experimental models of surgical intervention in the growing face: Cephalometric analysis of facial growth and relapse. In JA MeNamara, Jr, DS Carlson, and KA Ribbens (eds): The Effect of Surgical Intervention on Craniofacial Growth, Monograph 12 , Craniofacial Growth Series. Ann Arbor: Center for Human Growth and Development, The University of Michigan, pp. 11-72.

Carlson, DS, and Schneiderman, ED (in press) Cephalometric analysis of adaptations after lengthening of the masseter muscle in adult rhesus monkeys. Arch. Oral Biol.

Crawford, GNC (1954) An experimental study of muscle growth in the rabbit. J. Bone Joint Surg. 36(B):294303.

Dörfl, J (1980a) Migration of tendinous insertions. I. Causes and mechanisms. J. Anat. 131:179-195.

Dörfl, J (1980b) Migration of tendinous insertions. II. Experimental modifications. J. Anat. 131: 229-237.

Elgoyhen, JC, Riolo, ML, Graber, LW, Moyers, RE, and McNamara JA, Jr. (1972) Craniofacial growth in juvenile Macaca mulatta: A cephalometric study. Am. J. Phys. Anthropol. 36:369-376.

Goldspink, DF (1980) Physiological factors influencing protein turnover and muscle growth in mammals. In DF Goldspink (ed): Development and Specialization of Skeletal Muscle, Cambridge University Press, Cambridge, pp. 65-90.

Goldspink, G, and Williams, PE (1980) Development and growth of muscle. Adv. Physiol. Sci. 24:87-98.

Grant, PG, Buschang, PH, and Drolet, DW (1978) Positional relationships of structures attached to long bones during growth. Acta Anat. 102:378-384.

Grant, PG, and Hawes, MR (1977) Experimental modification of muscle migration in the rabbit. J. Anat. 123:361-367.

Grant, PG, Buschang, PH, Drolet, DW, and Pickerell, C. (1980) Invariance of the relative positions of structures attached to long bones during growth: cross-sectional and longitudinal studies. Acta Anat. 107:26-34.

Grant, PG, Buschang, PH, Drolet, DW, and Pickerell, C (1981) The effect of changes in muscle function and bone growth on muscle migration. Am. J. Phys. Anthropol. 54:547-554.

Griffin, G, Williams, PE, and Goldspink, G (1971) Region of longitudinal growth in striated muscle fibers. Nature 232:25-29.

Grimm, AF, and Katele, KV (1979) "Silverdust"-A tool to study growth interrelationships between bone, periosteum and muscle. Anat. Rec. 194:539-546.

Hurme, VO, and Van Wagenen, G (1961) Basic data on the emergence of permanent teeth in the rhesus monkey. Proc. Am. Phil. Soc. 105:40.

Lacroix, P (1951) The Organization of Bones. Penn: Blakiston.

MacKay, B, and Harrop, TJ (1969) An experimental study of the longitudinal growth of skeletal muscle in the rat. Acta Anat. 72:38-49.

McNamara, JA. Jr (1972) Neuromuscular and Skeletal Adaptations to Altered Orofacial Function. Monograph 1, Craniofacial Growth Series. Ann Arbor: Center for Human Growth and Development, The University of Michigan.

McNamara, JA, Carlson, DS, Yellich, GM, and Hendrickson, RP (1978) Musculoskeletal adaptation following orthognathic surgery. In DS Carlson and JA McNamara (eds): Muscle Adaptation in the Craniofacial Region. Monograph 8, Craniofacial Growth Series. Ann Arbor: Center for Human Growth and Develop ment, University of Michigan, pp. 91-131.

McNamara JA, Jr, and Graber, LW (1975) Mandibular growth in the rhesus monkey (Macaca mulatta). Am. J. Phys. Anthropol. 42:15-24.

McNamara, JA, Jr, Riolo, ML, and Enlow, DH (1976) Growth of the maxillary complex in the rhesus monkey (Macaca mulatta). Am. J. Phys. Anthropol. 44:1526.

Moss, ML, and Moss-Salentijn, L (1978) The muscle-bone interface: An analysis of a morphological boundary. In DS Carlson, and JA McNamara, Jr. (eds): Muscle Adaptation in the Craniofacial Region. Monograph 8 , Craniofacial Growth Series. Ann Arbor: Center for 
Human Growth and Development, The University of Michigan, pp. 39-72.

Muhl, ZF, and Grimm, AF (1974a) Longitudinal growth of striated muscle; a radiographic study. Growth 38:389-394.

Muhl, ZF, and Grimm, AF (1974b) Adaptability of rabbit digastric muscle to an abrupt change in length: $A$ radiographic study. Archs. Oral Biol. 19:829-833.

Schmidt, V (1927) Die Histogenese der quergestreiften Muskelfaser und des Muskelschnenuiber-ganges. Z. mihr.-anat. Forsch. 8:97-184.

Scott, J (1954) The growth and function of the muscles of mastication in relation to the development of the facial skeleton and of the dentition. Am. J. Orthod. 40:429499.

Speidel, CC (1934) Studies of living muscles. 1. Growth, injury and repair of striated muscles as revealed by prolonged observation of individual fibers in living frog tadpoles. Am. J. Anat. 62:179-236.

Stewart, DM (1972) The role of tension in muscle growth. In Regulation of Tissue and Organ Growth. New York: Academic Press, pp. 77-150.

Symons, NBB (1954) The attachment of the muscles of mastication. Brit. Dent. J. 96:76-81.

Tabary, JC, Tabary, C, Tardieu, C, Tardieu, G, and Goldspink, $G$ (1972) Physiological and structural changes in the cat's soleus muscle due to immobilization at different lengths by plaster casts. J. Physiol. 224:231244.

Tardieu, G, Tabary, JC, Tardieu, C, Tabary, C, Gaguard, $L$, and Lombard, M (1973) L'ajustement du nombre des sarcomères de la fibre musculaire à la longueur qui lui est imposeé. Rev. Neurol. (Paris) 129:21-42.

Williams, PE, and Goldspink, G (1971) Longitudinal growth of striated muscle fibers. J. Cell Sci. 9:751-767. 